\title{
Microstructure decomposition and unique mechanical properties in an ultrafine-grained Al-Zn alloy processed by high-pressure torsion
}

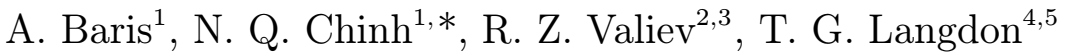 \\ ${ }^{1}$ Department of Materials Physics, Eötvös Loránd University, H-1117 Budapest, Pázmány Péter Sétány 1/A, Hungary \\ ${ }^{2}$ Institute of Physics of Advanced Materials, Ufa State Aviation Technical University, \\ 12 K. Marx str., Ufa 450000, Russia \\ ${ }^{3}$ Research Laboratory for Mechanics of New Nanomaterials, Saint Petersburg State Polytechnical University, \\ Saint Petersburg 195251, Russia \\ ${ }^{4}$ Departments of Aerospace \& Mechanical Engineering and Materials Science, University of Southern California, \\ Los Angeles, CA 90089-1453, U.S.A. \\ ${ }^{5}$ Materials Research Group, Faculty of Engineering and the Environment, University of Southampton, \\ Southampton SO17 1BJ, U.K.
}

Received 15 February 2015, received in revised form 23 May 2015, accepted 23 May 2015

\begin{abstract}
An ultrafine-grained (UFG) Al-30wt.\%Zn alloy was processed by high-pressure torsion (HPT) and then the mechanical and microstructural properties were investigated using depth-sensing indentations (DSI), focused ion beam (FIB), scanning electron microscopy (SEM) and differential scanning calorimetry (DSC). Emphasis was placed on the microstructure changes due to HPT processing as well as the effects of grain boundaries and the unusually high strain rate sensitivity. The deformation characteristics are explained by the formation of a Zn-rich phase which wets the $\mathrm{Al} / \mathrm{Al}$ grain boundaries and enhances the role of grain boundary sliding in this UFG alloy. The occurrence of intensive grain boundary sliding in this UFG alloy at room temperature was also demonstrated by deforming micro-pillars. It is shown that, as a result of grain boundary sliding, the plastic deformation process of the UFG samples remains stable even at the micro-scale without the intermittent flow and detrimental strain avalanches which are an inherent feature of micro-size conventional crystals. This result illustrates the advantage of using UFG materials for effective applications in micro-devices.
\end{abstract}

K e y wo r d s: grain boundary sliding, indentation, micro-pillars, strain rate sensitivity, ultrafine grains

\section{Introduction}

The Al-Zn alloys are probably the best known of all aluminum-based alloys. In this system there are some typical compositions such as the eutectic Al-95wt.\%Zn, the eutectoid Al-78wt.\%Zn and solid solutions having $\mathrm{Zn}$ contents lower than $31.6 \mathrm{wt. \%}$ : all of these materials have been extensively studied $[1-8]$. Recently, the supersaturated solid solution $\mathrm{Al}-30 \mathrm{wt} . \% \mathrm{Zn}$ alloy, which is an important basic material in the aluminum industry, was processed by severe plastic deformation (SPD) using high-pressure tor- sion (HPT) $[8,9]$. As a consequence of the severe deformation, an ultrafine-grained microstructure was obtained in this alloy and the material exhibited a superductility at room temperature with unusually high elongations up to $150 \%$ and relatively high strain rate sensitivities $[4,5]$. It is well known that the ultrafinegrained (UFG) materials produced by SPD generally exhibit only limited tensile ductilities of about 5-10\% and this is correlated with the extremely low strain rate sensitivity (SRS) of about $0.01-0.03$ for these materials [10]. It is also well established that UFG materials generally have reasonably saturated microstruc-

\footnotetext{
*Corresponding author: tel: +36-1-3722845; e-mail address: chinh@metal.elte.hu
} 
tures with a steady-state dislocation density [11] and under these conditions the role of the grain boundaries is enhanced in post-SPD deformation processes. Evidence is now available suggesting that grain boundary sliding (GBS) may occur more easily at room temperature (RT) in UFG metals [4-7, 12-15]. It should be noted that for the HPT-processed Al-30wt.\%Zn alloy both grain refinement and a decomposition $[2,6]$ characterized the microstructural changes associated with SPD.

In this report, some recent [4-7] and additional results are summarized describing the microstructural and the flow characteristics of the HPT-processed Al$-30 \mathrm{Zn}$ alloys and this permits an interpretation of the high ductility of this UFG alloy. In order to demonstrate the effect of the alloying (Zn) atoms, some of the investigated characteristics are compared with results obtained for UFG pure Al processed also by HPT and for an annealed Al-78wt.\%Zn eutectoid alloy.

\section{Experimental material and procedures}

The experiments were conducted using an aluminum-based alloy containing $30 \mathrm{wt} . \% \mathrm{Zn}$ prepared from high-purity components by vacuum induction melting. Disks having diameter of $20 \mathrm{~mm}$ and thickness of $0.8 \mathrm{~mm}$ were prepared from the as-cast alloy and then homogenized at $773 \mathrm{~K}$ for $5 \mathrm{~h}$ to give a solid solution microstructure with equiaxed grains having a mean size of $\sim 65 \mu \mathrm{m}$. These disks were processed by HPT for 5 turns at room temperature under quasi-constrained conditions [16] using a pressure of 6.0 $\mathrm{GPa}$ and a rotation speed of $1 \mathrm{rpm}$. Samples were cut from the HPT-processed disks for mechanical investigations at a distance of $5 \mathrm{~mm}$ from the sample centre. In order to follow the changes in the microstructural and mechanical properties of the UFG Al-30wt.\%Zn alloy, additional HPT-processed pure $\mathrm{Al}$ and additional Al-78wt.\%Zn eutectoid samples were also investigated. An as-cast high purity $(4 \mathrm{~N}) \mathrm{Al}$ was homogenized at $400{ }^{\circ} \mathrm{C}$ for $1 \mathrm{~h}$. Disks having thickness of $\sim 0.8 \mathrm{~mm}$ with diameter of $10 \mathrm{~mm}$ were processed by $\mathrm{HPT}$ at room temperature under an imposed pressure of $6.0 \mathrm{GPa}$ for 5 turns. The microstructure of the HPT-processed pure $\mathrm{Al}$ consisted also of equiaxed grains having an average size of $\sim 1.2 \mu \mathrm{m}$ where this grain size is consistent with that reported earlier for high-purity Al using ECAP [17, 18] and HPT [19]. The Al-78wt.\%Zn eutectoid samples were annealed at $473 \mathrm{~K}$ for $1 \mathrm{~h}$ to produce a reasonably homogeneously distributed microstructure of alternating Zn-rich and Al-rich phases [20].

Nano-compression was used to deform micro-pillars. These tests were undertaken at room temperature using a flat-ended conical diamond indenter within a UMIS device operating under a force $F$, that

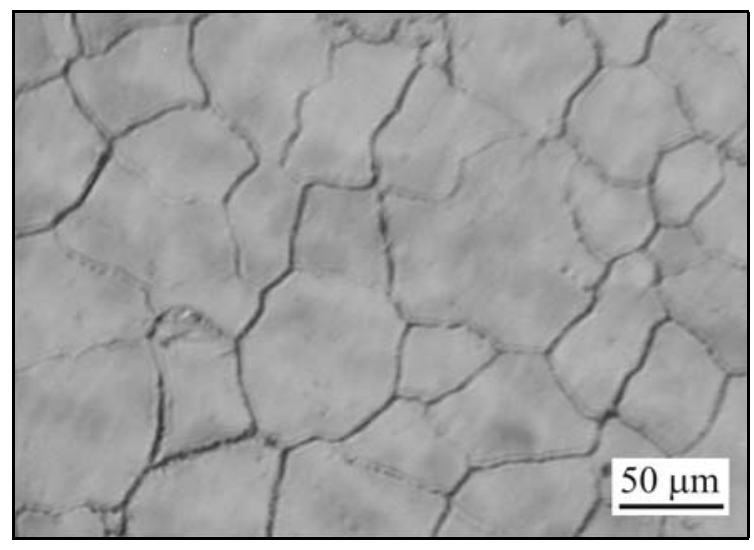

Fig. 1. Microstructure of the Al-30Zn alloy in an annealed state before HPT processing.

increased linearly with time up to $4 \mathrm{mN}$ using an imposed loading rate of $10^{-2} \mathrm{mN} \mathrm{s}^{-1}$. To avoid any possible damaging effect from extremely high strain avalanches, the indenter was automatically stopped at a maximum compression depth of $2 \mu \mathrm{m}$.

Micro-pillars having diameters of $\sim 3 \mu \mathrm{m}$ and heights of $\sim 10 \mu \mathrm{m}$ were prepared on the surfaces of the polished disks using scanning electron microscopy (SEM) and focused ion beam (FIB) functions in a multi-functional Quanta 3D operating at a voltage of $30 \mathrm{kV}$ for different currents of $\mathrm{Ga}^{+}$ions. Further details on the pillar-preparation were given earlier [6].

The existence of precipitates and different phases was examined by differential scanning calorimetry (DSC) using a Perkin-Elmer DSC2 calorimeter from 300 to $650 \mathrm{~K}$ with a heating rate of $20 \mathrm{~K} \mathrm{~min}^{-1}$.

\section{Experimental results and discussion}

\section{a) Microstructural and plastic characteristics of the HPT-processed Al-30Zn alloy}

Figure 1 shows the initial microstructure of the Al$-30 \mathrm{Zn}$ alloy having a coarse average grain-size of $50-60 \mu \mathrm{m}$ before HPT. It was shown earlier $[2,4]$ that during the HPT process the originally supersaturated solid solution microstructure decomposes as demonstrated in Fig. 2. The microstructure of the Al-30wt.\%Zn alloy after HPT contained equiaxed ultrafine Al grains having an average size of $300-400 \mathrm{~nm}$ with smaller Zn particles located mainly at the triple junctions of the $\mathrm{Al}$ grains. Recent transmission electron microscopy (TEM) and energy dispersive spectroscopy (EDS) results [7] on grain boundaries (GBs) show that more than 50 percent of the $\mathrm{Al} / \mathrm{Al}$ grain boundaries are wetted by Zn-rich layers and an example is visible in Fig. 3.

Applying nano- and micro-indentation tests [5], it 


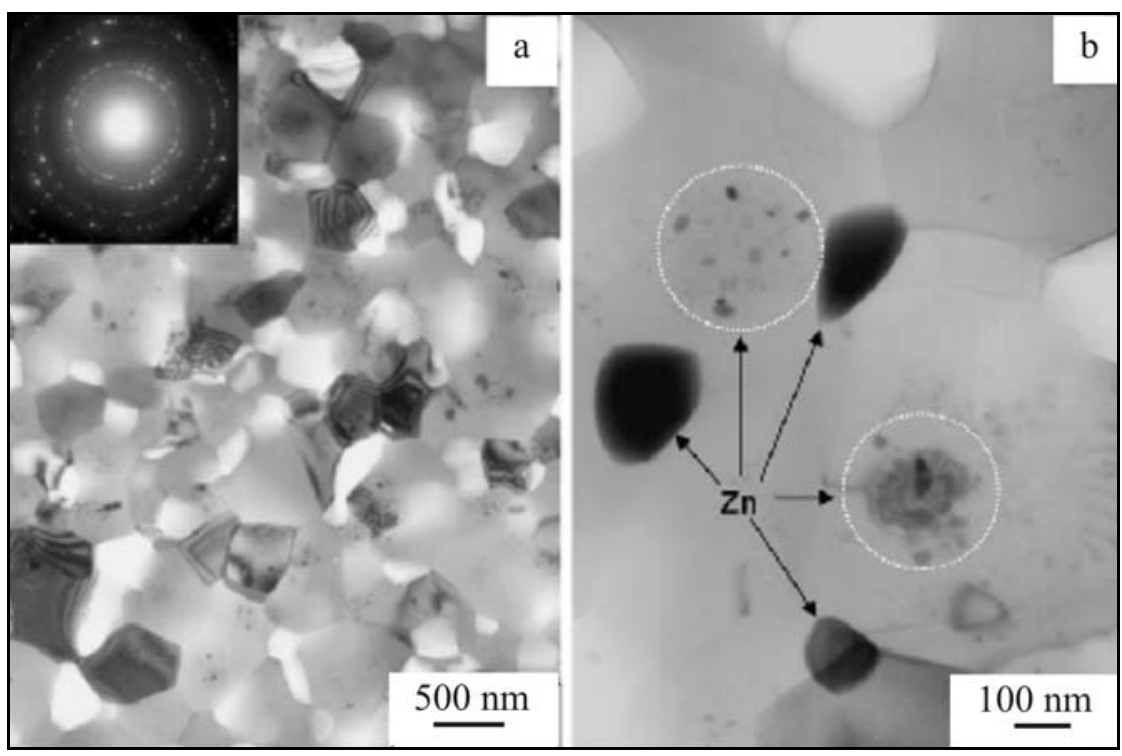

Fig. 2. Microstructure of the HPT-processed UFG Al-30Zn alloy at two magnifications [4].
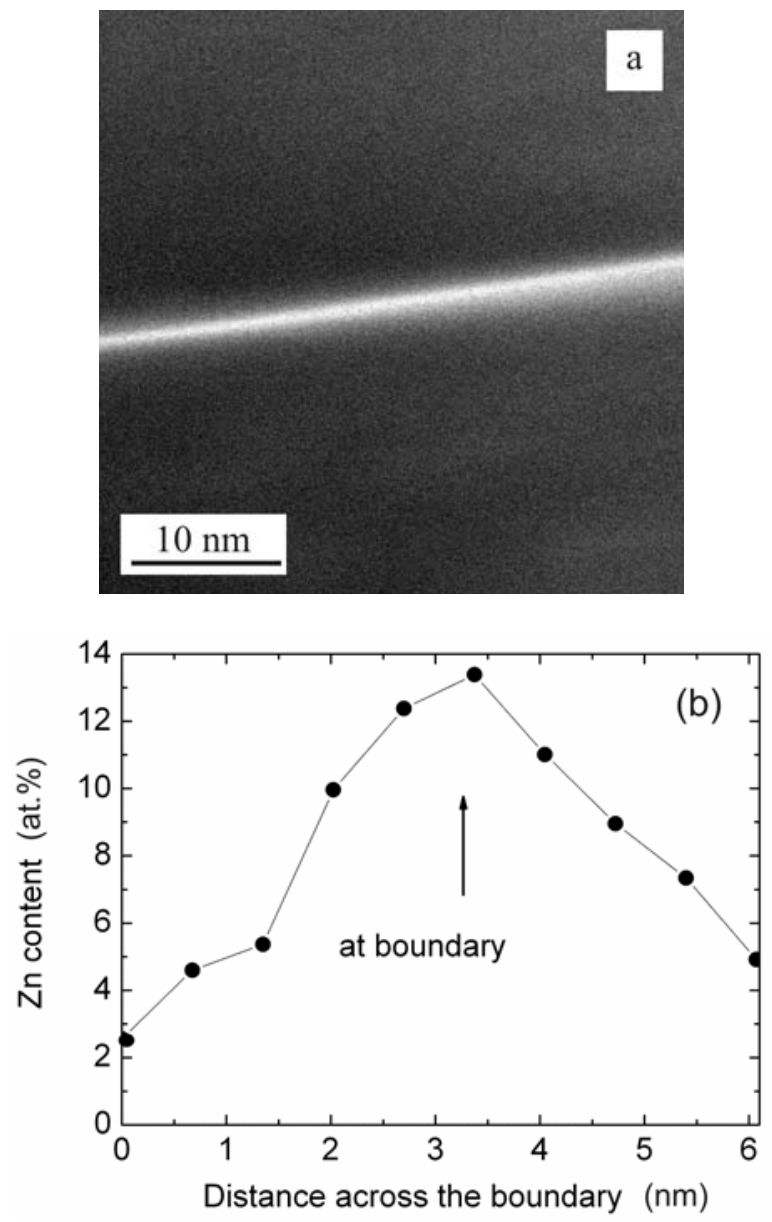

Fig. 3. Zn-rich layers in $\mathrm{Al} / \mathrm{Al}$ grain boundaries in the HPT-processed UFG Al-30Zn alloy, demonstrated by (a) TEM and (b) EDS line profile analysis showing the local Zn concentration along the boundary [7]. was demonstrated that the plastic deformation process of the UFG Al-30\% Zn can be characterized by an unusually high SRS and also an unusually rapid diffusion even at room temperature. The results obtained by both nano-and micro-indentation measurements show that the UFG Al-30Zn sample is much more sensitive to the deformation rate. Specifically, the SRS obtained on the UFG alloy is unusually high at about 0.22 which is seven times larger than for the conventional coarse-grained sample. It is important to note that, although a significantly higher SRS can be expected for UFG materials [21], the increased SRS is not the direct consequence of the fine-grained structure. For example, in the case of UFG $\mathrm{Al}$ and $\mathrm{Cu}$, the SRS remains very low at only about 0.01-0.03 [10].

Together with the increased SRS, a relatively low activation energy was obtained for this UFG alloy. The experimentally determined activation energy of $65 \mathrm{~kJ} \mathrm{~mol}^{-1}$ is lower than the values for self-diffusion in $\mathrm{Al}\left(142 \mathrm{~kJ} \mathrm{~mol}^{-1}\right.$ [22]), self-diffusion in $\mathrm{Zn}\left(92 \mathrm{~kJ} \mathrm{~mol}^{-1}[22]\right)$ or grain boundary diffusion in $\mathrm{Al}\left(84 \mathrm{~kJ} \mathrm{~mol}^{-1}[22]\right)$. Therefore, it is concluded that in the UFG Al-30Zn the process of plastic deformation is not controlled by self-diffusion of $\mathrm{Al}$ or $\mathrm{Zn}$. Furthermore, the activation energy $\left(65 \mathrm{~kJ} \mathrm{~mol}^{-1}\right)$ obtained for the UFG Al-30Zn alloy is lower than the value of $\sim 78 \mathrm{~kJ} \mathrm{~mol}^{-1}[23]$ obtained for the conventional eutectoid composition of Al-78wt.\% $\mathrm{Zn}$ which is a well known model alloy showing superplasticity. Considering the diffusion coefficient $D$, given as $D=D_{0} \exp (-Q / R T)$, where $D_{0}$ is a frequency factor, $Q$ is the appropriate activation energy for the diffusive process and $R$ is the universal gas constant, the low activation energy leads to a relatively high diffusion process at room temperature for the UFG 
Al-30Zn sample. Taking the value of $D_{0}$ in the range between $1.3 \times 10^{-5}$ and $1.7 \times 10^{-4} \mathrm{~m}^{2} \mathrm{~s}^{-1}[22]$ characterizing the diffusion processes of $\mathrm{Al}$ and $\mathrm{Zn}$, the diffusion coefficient of $\sim 1.6 \times 10^{-16} \mathrm{~m}^{2} \mathrm{~s}^{-1}$ estimated for flow of this alloy at RT $(300 \mathrm{~K})$ is about 3 orders higher than the value of $\sim 10^{-19} \mathrm{~m}^{2} \mathrm{~s}^{-1}$ characterizing $\mathrm{Al}$ self-diffusion along the $\mathrm{Al} / \mathrm{Al}$ grain boundaries or self-diffusion of $\mathrm{Zn}$. The diffusion coefficient of grain boundary diffusion in $\mathrm{Al}$ or that of self-diffusion in $\mathrm{Zn}$ may take values of $\sim 1.6 \times 10^{-16} \mathrm{~m}^{2} \mathrm{~s}^{-1}$ but only at a much higher temperature of $\sim 400 \mathrm{~K}$. The estimated value of the diffusion coefficient $D$ at room temperature for the HPT-processed UFG Al-30wt.\% Zn alloy correlates reasonably with the measured diffusivity $\left(\sim 10^{-15} \mathrm{~m}^{2} \mathrm{~s}^{-1}\right)$ for $\mathrm{Zn}$ along $\mathrm{Al} / \mathrm{Al}$ grain boundaries $[24,25]$. Considering also the existence of Zn-rich layers in the $\mathrm{Al} / \mathrm{Al}$ grain boundaries, it is reasonable to conclude that the occurrence of grain boundary sliding observed in this UFG alloy at room temperature is controlled primarily by $\mathrm{Zn}$ diffusion along the $\mathrm{Al} / \mathrm{Al}$ grain boundaries [7].

\section{b) Nano-compression measurements: effect of intensive grain boundary sliding}

The measured high diffusivity suggests a significant role for grain boundary sliding in the UFG Al-30Zn alloy. In order to check this prediction, micro pillars were prepared and deformed by nano-compression $[6$, $7]$.

Figure 4 shows typical compression curves obtained from micro-pillars on the surfaces of both conventional (annealed) and UFG Al-30Zn samples. In order to demonstrate also the usual strength and the flow processes of these samples, the experimentally measured load-depth curves (Fig. 4a) and the calculated stress-strain curves (Fig. 4b) are presented. As the compression process takes about $100 \mathrm{~s}$, the strain rate $(\dot{\varepsilon})$ of the flow process of the UFG micro-pillars may be estimated as $\sim 10^{-2} \mathrm{~s}^{-1}$. Since the flow stress is $\sim 200-300 \mathrm{MPa}$ at strains between 10 and $20 \%$, the stress-strain curves obtained for the UFG micro-pillars by nano-compression are quite similar to those of macroscopic samples deformed by tensile testing [4].

Considering the deformation of the micropillars, further essential differences are observed between the conventional and UFG materials. In the case of the conventional samples, where the pillars are single crystals fabricated from different coarse grains, the compression curves show the presence of visible strain avalanches. This is a well-known phenomenon characterizing the plasticity of micrometer-scale single crystals [26-30]. In contrast to this behaviour, the curves obtained for the UFG pillars are smooth and there is an absence of any strain avalanches. It is noted that the UFG micro-pillars are polycrystalline even at the micro-scale because of the exceptionally small grain
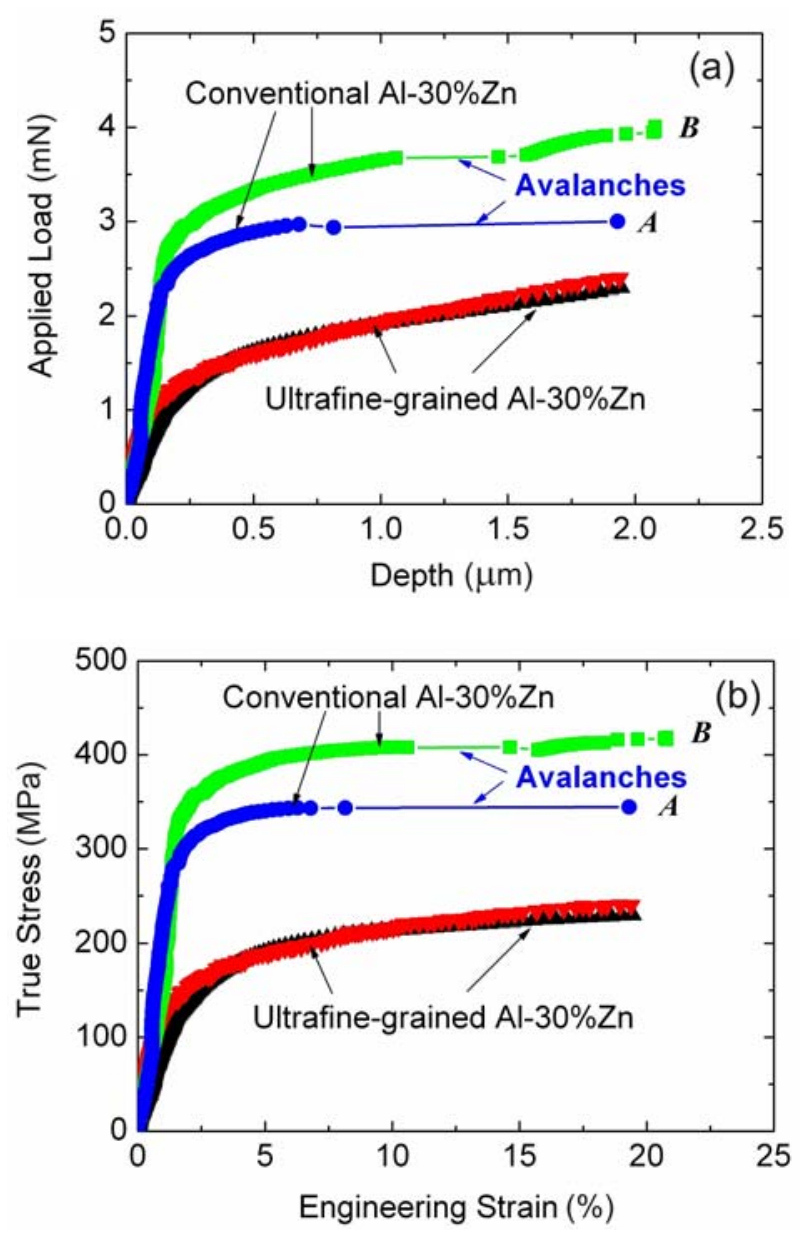

Fig. 4. Typical compression (a) load-depth and (b) stress-strain curves obtained for micro-pillars on the surfaces of both the conventional and HPT-processed UFG Al-30wt.\%Zn samples: note that the pillars on the conventional sample are single crystal pillars showing evidence for strain avalanches whereas the UFG pillars are polycrystalline and show the occurrence of stable deformation without avalanches [7].

size of $\sim 300-400 \mathrm{~nm}$. Therefore, when interpreting the plastic behaviour of these UFG samples, the role of the grain boundaries should be considered. It is well known that grain boundaries may act as obstacles for the moving dislocations but also they may become dislocation sources. Furthermore, if grain boundary diffusion is enhanced, leading to significant grain boundary sliding, the deformation process will take place primarily by the motion of grain boundaries. Because of these compensating effects, catastrophic slip events cannot take place in the polycrystalline pillars. Therefore, the smooth flow of the UFG samples is attributed unambiguously to the effects of the grain boundaries.

An examination of the compressed micro-pillars by SEM also revealed significant differences between the surface morphologies of the conventional and UFG samples. Figure 5 shows typical surface morphologies 

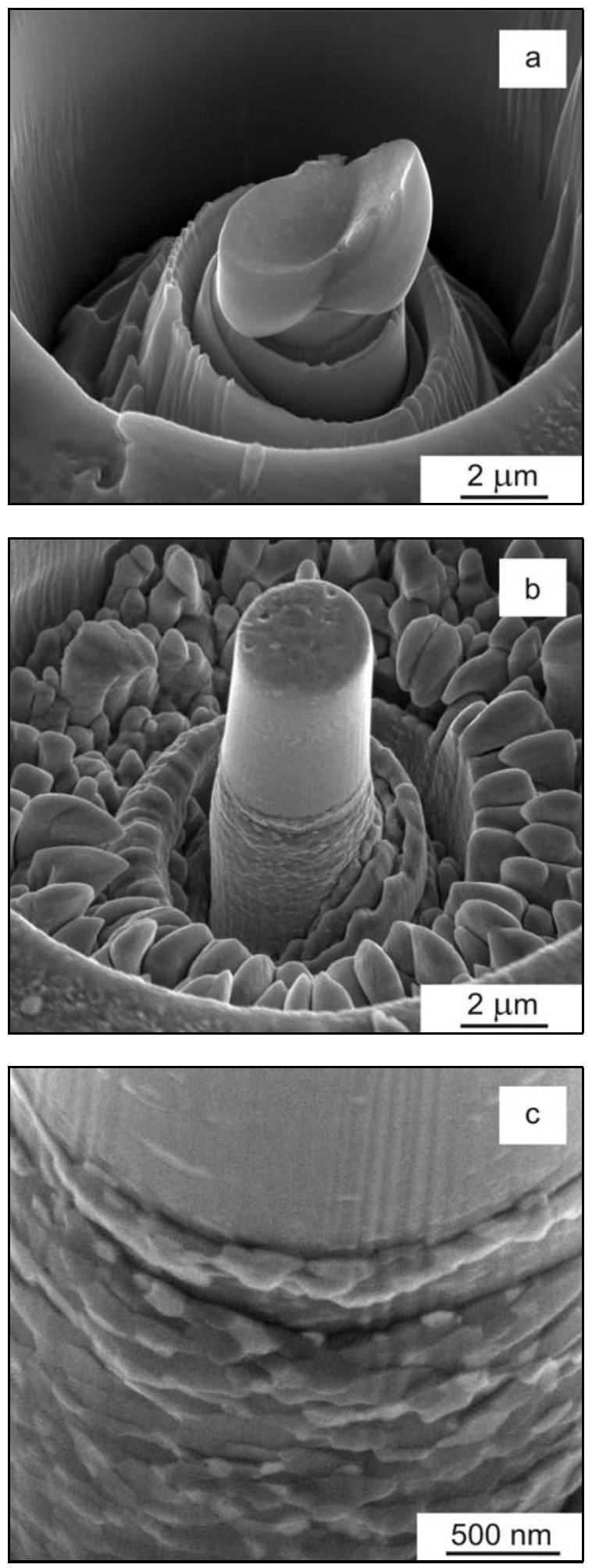

Fig. 5. The surface morphologies of compressed micro-pillars on the surface of (a) the conventional sample where strain localizations and extreme slip bands are observed corresponding to the avalanches visible in Fig. 2 and (b), (c) the HPT-processed UFG Al-30wt.\%Zn sample in low and high magnifications, respectively, where there is direct evidence for the occurrence of intensive GBS without localizations and extreme slip [7]. of both samples. For the conventional state, as in Fig. 5a, strain localizations and extreme slip bands are observed near to the direction of maximum shear stress at $45^{\circ}$ relative to the orientation of the compression stress. These strain localizations and extreme slip bands correlate with the strain avalanches visible in the compression curves of the micro-pillars on the conventional sample shown in Fig. 6. The large strain fluctuations lead to difficulties in plastically deforming micrometer-scale single crystals because of the possibility of catastrophic failure and for this reason the micrometer-sized samples of coarse-grained metals are not suitable for use in the fabrication of micro-devices.

In contrast to the case of conventional samples, no strain localizations and extreme slip bands are observed on the surface morphologies of the deformed UFG micro-pillars as in Figs. 5b,c at different magnifications. Furthermore, the surface morphologies demonstrate clearly the occurrence of intensive grain boundary sliding in the plastic deformation of the ultrafine-grained pillars. It can be seen for these samples that the compensating effect of the grain boundaries has converted the global maximum shear stress along the direction of $45^{\circ}$ into the motion of individual ultrafine-grains, resulting in deformation which has cylindrical symmetry as rings of refined grains are displaced around the sample. The observations shown in Figs. 5b,c are consistent with the smooth compression load-depth curves of the UFG sample shown in Fig. 4. The stable deformation by GBS of the UFG micro-pillars, without the occurrence of any catastrophic avalanches, emphasizes the advantage of the GBS mechanism and suggests a potential for using these UFG materials in the fabrication of micro-devices.

c) DSC measurements: effect of decomposition on the thermograms

The explanation for the unusually high diffusivity and plastic behaviour is due to the development of thin layers of a Zn-rich grain boundary phase. In this model, the high ductility state corresponds to the UFG structure where large fractions of the $\mathrm{Al} / \mathrm{Al}$ boundaries are wetted with thin Zn-rich layers formed during the HPT processing [3]. Therefore, it is necessary to consider the nature of the Zn-rich phase which provides lubrication and thereby facilitates easier GB sliding and consequently enhanced ductility in the HPT-processed UFG Al-30Zn alloy.

Figure 6 shows DSC thermograms taken on the conventional and UFG Al-30Zn samples. It can be seen that there is a significant difference between these two DSC curves. For the conventional sample in Fig. 6a, well defined endothermic peaks are observed showing the dissolution of Guinier-Preston (GP) zones at the lower temperature peak and then the solid solution 

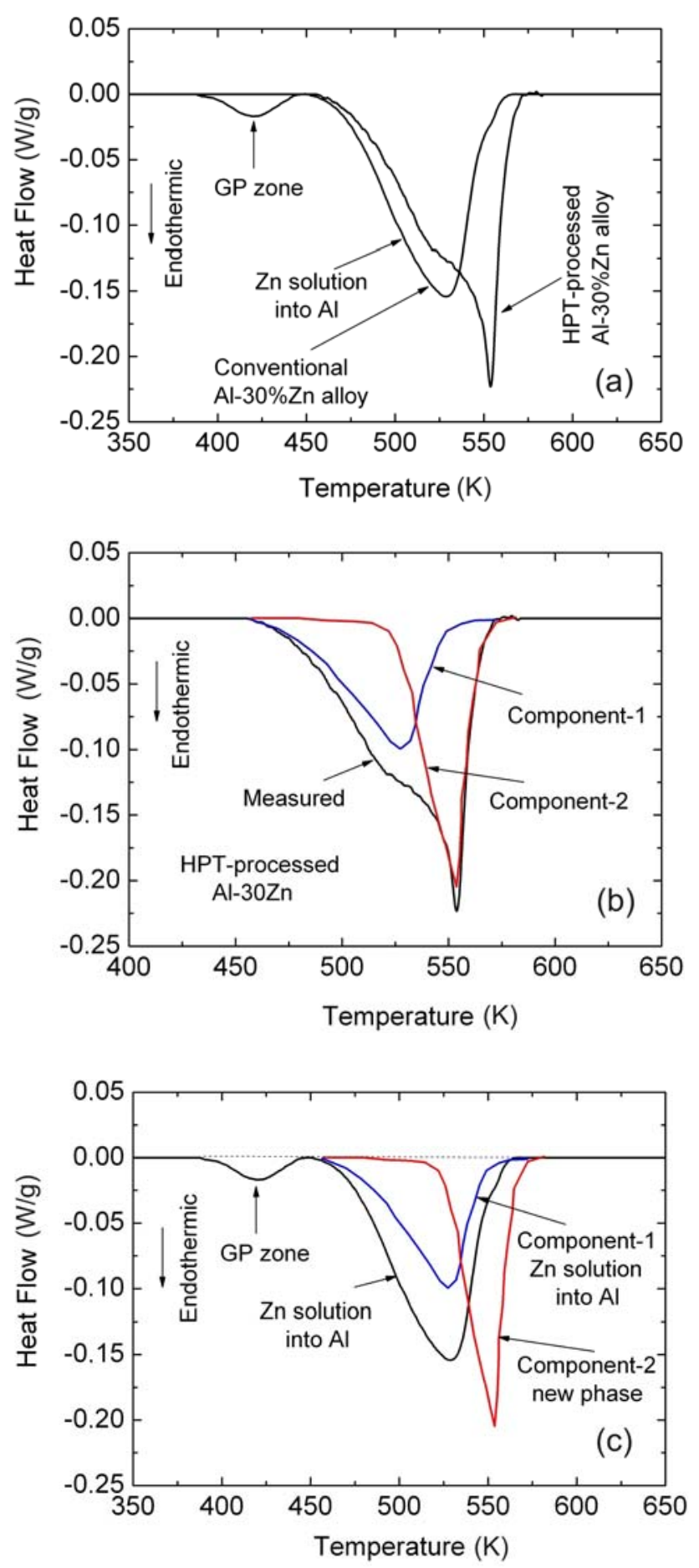

Fig. 6. DSC measurements showing: (a) thermograms obtained on conventional and HPT-processed Al-30wt.\%Zn alloys, (b) two components of the DSC thermogram obtained on HPT-processed Al-30wt.\%Zn alloy and (c) thermogram of the conventional Al-30wt.\%Zn and two components of HPT-processed Al-30wt.\%Zn alloy.

of $\mathrm{Zn}$ in $\mathrm{Al}$ at the higher temperature peak [31]. The curve obtained for the UFG alloy, also in Fig. 6a, contains only one shoulder-shape endothermic peak in-

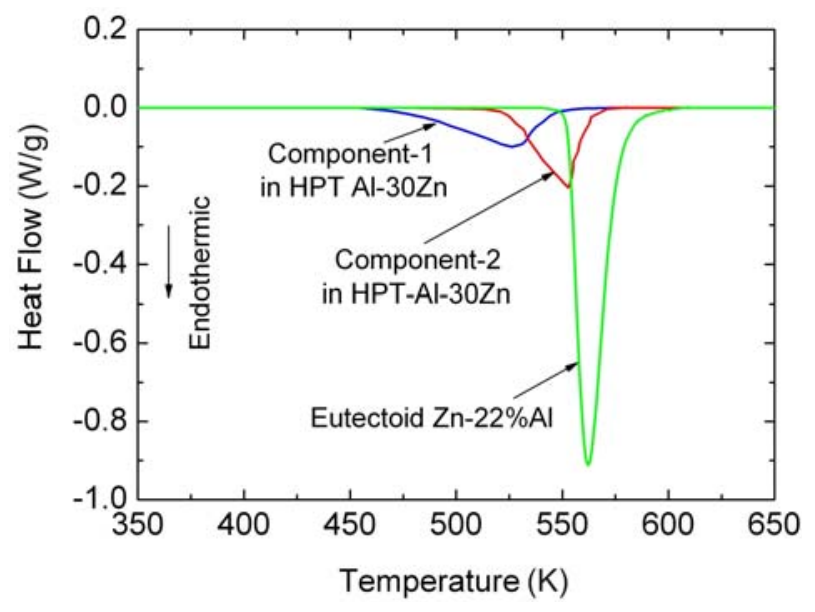

Fig. 7. DSC measurements showing the thermogram obtained on the eutectoid Al-78wt.\%Zn alloy and the two components of the thermogram obtained on HPT Al$-30 \mathrm{wt} . \% \mathrm{Zn}$, indicating the presence of a new and near eutectoid phase in the HPT-processed Al-30wt.\%Zn alloy.

dicating significant changes in the microstructure of the Al-30Zn alloy after the HPT processing. It can be seen clearly that after the HPT process there is no peak at low temperatures showing that GP zones were not formed in the HPT-processed sample. This confirms the decomposition of the supersaturated (conventional) state as was also observed by an earlier transmission electron microscopy (TEM) investigation $[2,4]$. Furthermore, the single shoulder-shape endothermic peak is shifted to a higher temperature relative to the temperature of the second peak of the conventional sample, suggesting a phase-transition in this alloy due to the SPD in the HPT processing.

Analysis shows that this thermogram obtained on the HPT-processed $\mathrm{Al}-30 \mathrm{Zn}$ is composed of two components as in Fig. 6b where one (designated component-1) is similar to the second peak of the conventional sample (see Fig. 6c) showing also the solid solution of $\mathrm{Zn}$ in $\mathrm{Al}$. This component represents solution of the $\mathrm{Zn}$ particles, which are located mainly at the triple junctions of the $\mathrm{Al}$ grains [4], into the $\mathrm{Al}$ matrix in the HPT-processed $\mathrm{Al}-30 \mathrm{Zn}$ alloy. The second component (designated component-2 in Fig. 6b) indicates the presence of a new phase as the DSC curve characterizing this component is unusual and is not observed in the conventional sample. It should be noted that the peak temperature of this component-2 is $\sim 25 \mathrm{~K}$ higher than for the second peak of the conventional sample (see Fig. 6c).

In Fig. 7, both the curves of component-1 and component-2 are re-plotted together with the thermogram recorded from a eutectoid composition of Al$-78 \mathrm{wt} . \% \mathrm{Zn}$. It can be seen that the endothermic peak of the DSC curve of component-2 is very close to that from an eutectoid sample. This result from the 
DSC measurements leads to the conclusion that the new phase indicated by component- 2 has a composition close to that of the well known eutectoid Al-78wt.\%Zn alloy. This Zn-rich component-2, a near-eutectoid phase, is certainly in the $\mathrm{Al} / \mathrm{Al}$ grain boundaries providing Zn-rich boundaries which produce super-ductility by enhancing the diffusivity of $\mathrm{Zn}$ between the $\mathrm{Al} / \mathrm{Al}$ grains. It should be noted that the volume fraction of this new near-eutectoid phase is low in the HPT-processed Al-30wt.\%Zn sample, leading to a lower heat of dissolution with a smaller corresponding area relative to that obtained for the eutectoid sample.

The complex shape of the DSC curves in the HPT-processed Al-30Zn alloys driven by the existence of GB phases was also observed in an earlier report [3]. Thus, further investigations are now needed to provide a comprehensive explanation for the origin of these unusual Zn-rich layers which are formed in the HPT-processed Al-30wt.\%Zn alloy.

\section{Summary and conclusions}

1) The characteristics of room temperature plastic deformation and microstructural properties of an HPT-processed, ultrafine-grained Al-30wt.\%Zn alloy were investigated using nano-indentation, nano-compression and differential scanning calorimetry.

2) Unique observations reveal the occurrence of intensive grain boundary sliding at room temperature in the UFG Al-30wt.\%Zn alloy, thereby confirming the basic deformation mechanism even in samples having a size at the micrometer scale. The occurrence of sliding provides an explanation for the unusually high SRS and the high ductilities in this material. Furthermore, as a result of grain boundary sliding, the plastic deformation of the UFG samples remains stable even at the micro-scale without the occurrence of intermittent flow and detrimental strain avalanches which characterize micro-sized conventional crystals. This stability demonstrates the potential for using UFG materials for their effective application in micro-devices.

3) It is shown that, together with a decomposition of the supersaturated state, a Zn-rich new phase forms in the ultrafine-grained microstructure due to the severe plastic deformation imposed during high-pressure torsion. The enhanced diffusivity of $\mathrm{Zn}$ along the $\mathrm{Al} / \mathrm{Al}$ grain boundaries promotes flow by grain boundary sliding and leads to an increased ductility in the UFG Al-30wt.\%Zn alloy. These results demonstrate the beneficial improvement in ductility that follows from enhanced diffusion of $\mathrm{Zn}$ along the grain boundaries in a UFG $\mathrm{Al}$ alloy after processing by severe plastic deformation and accordingly the results suggest a new and alternative procedure for develop- ing ductility in ultrafine-grained materials processed using SPD procedures.

\section{Acknowledgements}

This paper is dedicated to Professor Pavel Lukáč on the occasion of his 80th birthday.

This work was supported by the Hungarian Scientific Research Fund (OTKA) under Grants No. K109021 and K109570 (NQC), the Russian Federal Ministry for Education and Science through the Russian Program "5-100-2020" at Research Laboratory for Mechanics of New Nanomaterials, St Petersburg State Polytechnical University, Saint Petersburg 195251, Russia (RZV) and by the European Research Council under ERC Grant Agreement No. 267464-SPDMETALS (TGL). The European Union and the European Social Fund provided financial support for this project under Grant Agreement No. TÁMOP 4.2.1./B-09/1/KMR-2010-0003.

\section{References}

[1] López, G. A., Mittemeijer, E. J., Straumal, B. B.: Acta Mater, 52, 2004, p. 4537. doi:10.1016/j.actamat.2004.06.011

[2] Straumal, B. B., Baretzky, B., Mazilkin, A. A., Phillipp, F., Kogtenkova, O. A., Volkov, M. N., Valiev, R. Z.: Acta Mater, 52, 2004, p. 4469. doi:10.1016/j.actamat.2004.06.006

[3] Straumal, B. B., Valiev, R. Z., Kogtenkova, O. A., Zieba, P., Czeppe, T., Bielanska, E., Faryna, M.: Acta Mater, 56, 2008, p. 6123. doi:10.1016/j.actamat.2008.08.021

[4] Valiev, R. Z., Murashkin, M. Y., Kilmametov, A., Straumal, B. B., Chinh, N. Q., Langdon, T. G.: J Mater Sci, 45, 2010, p. 4718. doi:10.1007/s10853-010-4588-z

[5] Chinh, N. Q., Csanádi, T., Gyri, T., Valiev, R. Z., Straumal, B. B., Kawasaki, M., Langdon, T. G.: Mater Sci Eng A, 543, 2012, p. 117. doi:10.1016/j.msea.2012.02.056

[6] Chinh, N. Q., Gyri, T., Valiev, R. Z., Szommer, P., Varga, G., Havancsák, K., Langdon, T. G.: MRS Comm, 2, 2012, p. 75. doi:10.1557/mrc.2012.11

[7] Chinh, N. Q., Valiev, R. Z., Sauvage, X., Varga, G., Havancsák, K., Kawasaki, M., Straumal, B. B., Langdon, T. G.: Adv Eng Mater, 16, 2014, p. 1000. doi:10.1002/adem.201300450

[8] Alhamidi, A., Edalati, K., Horita, Z., Hirosawa, S., Matsuda, K., Terada, D.: Mater Sci Eng A, 610, 2014, p. 17. doi:10.1016/j.msea.2014.05.026

[9] Zhilyaev, A. P., Langdon, T. G.: Prog Mater Sci, 53, 2008, p. 893. doi:10.1016/j.pmatsci.2008.03.002

[10] Meyers, M. A., Mishra, A., Benson, D. J.: JOM, 58(4), 2006, p. 41. doi:10.1007/s11837-006-0214-6

[11] Chinh, N. Q., Csanádi, T., Gubicza, J., Langdon, T. G.: Acta Mater, 58, 2010, p. 5015. doi:10.1016/j.actamat.2010.05.036

[12] Chinh, N. Q., Szommer, P., Horita, Z., Langdon, T. G.: Adv Mater, 18, 2006, p. 34. doi:10.1002/adma.200501232 
[13] Chinh, N. Q., Szommer, P., Csanádi, T., Langdon, T. G.: Mater Sci Eng A, 434, 2006, p. 326. doi:10.1016/j.msea.2006.07.014

[14] Ivanov, K. V., Naydenkin, E. V.: Scripta Mater, 66, 2012, p. 511. doi:10.1016/j.scriptamat.2011.12.039

[15] Ivanov, K. V., Naydenkin, E. V.: Mater Sci Eng A, 606, 2014, p. 313. doi:10.1016/j.msea.2014.03.114

[16] Figueiredo, R. B., Pereira, P. H. R., Aguilar, M. T. P., Cetlin, P. R., Langdon, T. G.: Acta Mater, 60, 2012, p. 3190. doi:10.1016/j.actamat.2012.02.027

[17] Iwahashi, Y., Horita, Z., Nemoto, M., Langdon, T. G.: Acta Mater, 45, 1997, p. 4733. doi:10.1016/S1359-6454(97)00100-6

[18] Iwahashi, Y., Horita, Z., Nemoto, M., Langdon, T. G.: Acta Mater, 46, 1998, p. 3317. doi:10.1016/S1359-6454(97)00494-1

[19] Xu, C., Horita, Z., Langdon, T. G.: Acta Mater, 55, 2007, p. 203. doi:10.1016/j.actamat.2006.07.029

[20] Kawasaki, M., Ahn, B., Langdon, T. G.: Mater Sci Eng A, 527, 2010, p. 7008. doi:10.1016/j.msea.2010.07.090

[21] Ahmed, N., Hartmaier, A.: Acta Mater, 59, 2011, p. 4323. doi:10.1016/j.actamat.2011.03.056

[22] Frost, H. J., Ashby, M. F.: Deformation-Mechanism Maps: The Plasticity and Creep of Metals and Ceramics. Oxford, Pergamon Press 1982.
[23] Mohamed, F. A., Shei, S. A., Langdon, T. G.: Acta Metall, 23, 1975, p. 1443. doi:10.1016/0001-6160(75)90153-4

[24] Mehrer, H. (ed.): Diffusion in Solid Metals and Alloys. Berlin, Springer 1990.

[25] Kaur, I., Gust, W., Kosma, L.: Handbook of Interphase and Grain Boundary Diffusion. Stuttgart, Ziegler Press 1989.

[26] Dimiduk, D. M., Woodward, C., LeSar, R., Uchic, M. D.: Science, 312, 2006, p. 1188. doi:10.1126/science.1123889

[27] Greer, J. R., De Hosson, J. T. M.: Prog Mater Sci, 56, 2011, p. 654. doi:10.1016/j.pmatsci.2011.01.005

[28] Uchic, M. D., Shade, P. A., Dimiduk, D. M.: Ann Rev Mater Res, 39, 2009, p. 361. doi:10.1146/annurev-matsci-082908-145422

[29] Csikor, F. F., Motz, C., Weygand, D., Zaiser, M., Zapperi, S.: Science, 318, 2007, p. 251. doi:10.1126/science.1143719

[30] Ispánovity, P. D., Groma, I., Györgyi, G., Csikor, F. F., Weygand, D.: Phys Rev Lett, 105, 2010, p. 085503. doi:10.1103/PhysRevLett.105.085503

[31] Mondolfo, L. F.: Aluminum Alloys: Structure and Properties. London, Butterworths 1976. 